\title{
Auctions with costly information acquisition ${ }^{1}$
}

\author{
Jacques Crémer ${ }^{2}$ \\ Yossi Spiegel $^{3}$ \\ IDEI-GREMAQ, Université de Toulouse \\ Tel Aviv University \\ Charles Z. Zheng ${ }^{4}$ \\ Iowa State University
}

August 2007 
${ }^{1}$ For helpful comments we thank George Deltas, David Martimort, an anonymous referee, and seminar participants in Mannheim, Rutgers, Tel Aviv, Toulouse, the Society for Economic Design 2002 conference in New York, and the 2003 North American Summer Meetings of the Econometric Society in Evanston, IL. Yossi Spiegel thanks the IIBR for financial assistance and Charles Zheng thanks the NSF for grant SES-0214471.

${ }^{2}$ IDEI and GREMAQ, Toulouse School of Economics, Tel: +33(0)561 128634, email: jacques@cremeronline.com

${ }^{3}$ Recanati Graduate School of Business Administration, Tel Aviv University, Ramat Aviv, Tel Aviv, 69978, Israel, Tel: 972-3-640-9063, email: spiegel@post.tau.ac.il, http://www.tau.ac.il/ spiegel/.

${ }^{4}$ Department of Economics, Iowa State University, 260 Heady Hall, Ames, IA 50011, email: czheng@iastate.edu. 


\begin{abstract}
We characterize optimal selling mechanisms in auction environments where bidders must incur a cost to learn their valuations. These mechanisms specify for each period, as a function of the bids in previous periods, which new potential buyers should be asked to bid. In addition, these mechanisms must induce the bidders to acquire information about their valuations and to reveal this information truthfully. Using a generalized Groves principle, we prove a very general "full extraction of the surplus" result: the seller can obtain the same profit as if he had full control over the bidders' acquisition of information and could have observed directly their valuations once they are informed. We also present appealing implementations of the optimal mechanism in special cases.
\end{abstract}


If you see this, and we have not made any mistake, you are seeing a version of this paper compiled so as to be easier to read on a screen. Another version, more appropriate for printing, is available. If you find this version useful, or if you have any other comment, please tell us.

Hint If you are using Acrobat and follow an hyperlink, you can get back to the original place by doing Alt-left arrow. 


\section{Introduction}

Most of the auction literature assumes that the bidders have private information about their willingness to pay and that they use this information strategically. In reality, however, bidders may need to incur a cost to discover how much they value the object that is up for sale. For instance, when governments sells spectrum, telecommunication companies must expend resources to find out how much they value this spectrum, especially if they are going to use it for new services for which the underlying technologies are not yet fully developed. Likewise, potential bidders for the assets of a bankrupt firm must evaluate the potential synergies with their existing assets.

A number of authors have studied auctions with endogenous entry and information acquisition. ${ }^{1}$ This literature considers one-shot auctions to which it appends a preliminary stage in which potential bidders can simultaneously and independently decide whether or not to enter and/or acquire costly information. It typically studies exogenously given auction formats and studies the bidders' strategies, sometimes comparing the profits of the seller under different formats.

A few authors have considered optimal auctions with endogenous acquisition of information. Bergemann and Pesendorfer (2001) consider a (one shot) optimal auction problem in which the seller can choose the accuracy with which bidders (costlessly) learn their valuations prior to the auction. Bergemann and Välimäki (2002) consider a (one shot) general mechanism design problem in which agents can acquire costly information of varying qualities before participating in the mechanism. In both cases though, the acquisition of information is done simultaneously by all

\footnotetext{
${ }^{1}$ See, for instance, Chakraborty and Kosmopoulou (2001), Engelbrecht-Wiggans (1993), Levin and Smith (1994), Matthews (1984), McAfee and McMillan (1987), Persico (2000), Stegeman (1996), Tan (1992), Ye (2004), and Klemperer (1999) for a survey.
} 
agents before they participate. However, in many cases it is optimal to examine the willingness of the potential bidders to pay sequentially, so that the number of bidders who enter the mechanism and the time at which they enter is an integral part of the mechanism design. In general then, optimal mechanisms will be multistage: buyers will enter the mechanism in turn and will participate in a sequence of auctions rather than in a one-shot auction.

Our aim in this paper is to characterize optimal selling mechanisms when potential buyers do not know at the outset how much they value the good for sale but can privately learn this value at a cost. Our main result is that the seller can, in very general circumstances, completely overcome the buyers' incentive problems, and loses no profit due to the fact that the buyers' have private information about their value once they acquired it . This result is very general: it holds whether or not the buyers' types are independent, whether or not the acquisition of information is observable, and can be extended to cases where the acquisition of information proceeds through several stages. The proof is constructive: given the search procedure built under the assumption that the bidders are honest, we show that it is possible to complement it with transfers that induce the bidders to truthfully reveal the value that they attach to the object for sale. Therefore, under our assumptions, the difficulty in finding an optimal auction format is the "Operations Research" problem of finding the optimal search procedure, not the economic problem of giving incentives to the buyers.

We believe that our main result is important for at least three reasons. First, it fully identifies the optimal mechanism in the setup used by most of the literature on endogenous acquisition of information in auctions. Second, in order to prove this result in its full generality, we introduce a dynamic extension of the Vickrey-Clarke-Groves mechanism. The Vickrey-Clarke-Groves insight that under some circumstances it is possible to make the agents internalize the consequences of their announcements has been a linchpin of mechanism design, and a precise description of the 
cases where it can be extended to multi-period setups should help think through dynamic problem.

Third, as far as we know, only Burguet (1996) has studied optimal procurement mechanisms in a setting similar to ours. ${ }^{2}$ Translated into our auction setting, his model considers a seller who faces a number of potential buyers whose valuations are i.i.d. The buyers need to incur a cost to learn their respective valuations and can do so only one at a time. In our setting, the buyers' valuations need not be independent and search need not be strictly sequential. ${ }^{3}$ However, when the bidders' valuations are independent (but not necessarily i.i.d.), we provide a generalization of Burguet's results which provides precise guidance for the construction of sequential auctions.

The paper is organized as follows. After introducing some notation and proving some preliminary results in Section 2, we discuss in Section 3 optimal mechanisms in special cases where they have nice interpretable properties. We develop our most general results in Sections 4 and 5 . In Section 4, we present a mechanism that implements the first-best search procedure and show that the mechanism induces truth telling. In Section 5 we show that this mechanism provides buyers with proper incentives to acquire information. We conclude in Section 6.

${ }^{2}$ Three other papers, McAfee and McMillan (1988) as well as Crémer, Spiegel, and Zheng (2006 and 2007), study optimal auctions in which the principal needs to incur a cost in order to communicate with potential bidders. In these papers, the participation constraints of the bidders are interim rather than ex ante as in the current paper.

${ }^{3}$ We discuss the differences between Burguet's framework and ours further in Section 3.3. 


\section{The model and preliminary analysis}

\subsection{Utilities and information acquisition}

The seller is selling a single good, for which he has zero value. There is a finite set $I$ of potential buyers, or briefly buyers. The time horizon consists of discrete periods. Ex ante, a buyer $i$ 's utility from consuming the good, which we will call his value, is uncertain. This value, $v_{i}$ for buyer $i$, is drawn from a measurable set $V_{i}$, with a strictly positive density on that set, but its exact realization is unknown to the buyer or to the seller until the buyer acquires information. For our most general results, the $v_{i}$ s need not be independent from each other. When a buyer acquires information he perfectly learns his value. ${ }^{4}$ It is common knowledge that the cost that buyer $i$ bears when acquiring information is $c_{i} \geq 0$.

We make assumptions that ensure that it is not optimal to have buyers participating in the auction without acquiring information (see below). This implies that in an optimal search procedure, there is no point in bypassing the information acquisition steps before selling the good to a buyer. Moreover, we assume that the seller can control the buyers' access to information and can prevent buyers from acquiring information prematurely before he asks them to do so. For the moment we will also assume that the acquisition of information is contractible: each buyer must acquire information when the seller asks him to do so and only then. In Section 5 however we show that this assumption is not necessary for our results to go through: we prove that the mechanism that we construct in Section 4 also provides buyers with proper incentives to acquire information. A

\footnotetext{
${ }^{4}$ Adding more notation, our model and results can be extended to situations where a buyer cannot acquire information until a certain time and information acquisition may take several periods.
} 
buyer is said to be uninformed before he acquires information, and informed afterwards.

The payoffs of the seller and every buyer are of the quasi-linear form standard in mechanism design, which implies that they are risk neutral. In particular, given that the value of the good for the seller is zero, the seller's payoff is equal to the expected discounted payments that the buyers make, while the payoff of each buyers is equal to the discounted value of the good from his perspective, conditional on him winning it, minus his discounted expected payments to the seller and minus his discounted cost of acquiring information. In any period $t$, the discount factor for the payoff available in the next period is $\delta_{t} \in(0,1]$, identical for everyone. In order to simplify notation, we will assume, contrary to the convention in the search literature, that when a buyer acquires information in a given period, he can consume the good in that same period.

Note on information acquisition. Using the terminology of Crémer, Khalil and Rochet (1998a), we assume that information acquisition is "productive" in the sense that the information is needed to begin consuming the good. ${ }^{5}$ For instance, a buyer of a controlling block of shares in a firm, must examine the firm's books and evaluate the firm's strategy (i.e., "acquire information") before exercising his control over the firm. Similarly, a builder who wins a construction contract must examine the plans, evaluate the sources of supply, etc., before beginning the construction. In these cases, all the information acquisition costs incurred in order to choose a bid would have been incurred anyway after winning the auction. Then, the seller never loses by asking the bidder to collect information before acquiring the good; this is clear when there is no asymmetry of information, as in the optimal search procedure defined in section 2.2 and consequently, it is also

\footnotetext{
${ }^{5}$ In general, information acquisition could also be "strategic." That is, the information allows the bidder to enjoy information rents but is not needed in order to consume the good.
} 
true for the optimal mechanisms which we define below.

\subsection{Search procedures}

In this subsection, we define "search procedures", which provides instructions on which buyers should acquire information at each period, when to end the process, and which buyer should eventually get the good. A search procedure then corresponds to the Operations Research part of the seller's problem assuming that once $c_{i}$ is spent, the seller learns buyer $i$ 's value, $v_{i}$, along with buyer $i$. In 2.3, we define selling mechanisms, which take into account the fact that each buyer $i$ privately learns $v_{i}$ and must be induced to reveal it truthfully. We make a careful distinction between these two concepts because our main aim is to prove Theorem 1, which states that under a fairly weak condition, it is always possible to complement the optimal search procedure with appropriate transfers that transform it into a selling mechanism.

A search procedure provides instructions on which buyers should acquire information at each period, when to end the process, and which buyer should eventually get the good. All of these decisions are based on the values of those who have already acquired information. ${ }^{6}$ To avoid triviality, we assume that the optimal search is such that at least one buyer acquires information in period 1 and until the procedure stops, at least one buyer acquires information in every period. ${ }^{7}$

\footnotetext{
${ }^{6}$ It is helpful to think about a search procedure as the analog of "allocation" in a traditional mechanism design framework in which agents know their values at the outset. Like an allocation, a search procedure is a function of realized values. (Whether these values are thruthfully revealed or not is an issue that will be dealt with later when we define our mechanism).

${ }^{7}$ As long as the mechanism does not stop, it is never suboptimal for at least one buyer to get information and, if $\delta_{t}<1$ for all $t$, then this is strictly optimal.
} 
Given this assumption, a search procedure takes the following form. In period 1, a set $I_{1}$ of buyers acquire information. Let $\mathbf{v}^{1}$ be the information profile at the end of period 1 which specifies the values of buyers in $I_{1}$ and assigns the value $\emptyset$ for buyers who are not in $I_{t}$. For instance, if $I_{1}=\{1,2,3\}$ and $v_{1}=2, v_{2}=0$, and $v_{3}=6$, then $\mathbf{v}^{1}=(2,0,6, \emptyset, \ldots, \emptyset)$. Contingent on $\mathbf{v}^{1}$, the search either ends and the buyer with the highest known value gets the good, or the search continues to period 2. For any $t \geq 2$, let $\mathbf{v}^{t-1}$ be the information profile at the end of period $t-1$. Given $\mathbf{v}^{t-1}$, a set $I_{t}\left(\mathbf{v}^{t-1}\right)$ of previously uninformed buyers acquire information in period $t$ and $\mathbf{v}^{t}$ is obtained from $\mathbf{v}^{t-1}$ by replacing the $\emptyset$ corresponding to the buyers in $I_{t}\left(\mathbf{v}^{t-1}\right)$ by their true values. For instance, in the context of our previous example, if $I_{2}\left(\mathbf{v}^{1}\right)=\{4,6\}, v_{4}=7$ and $v_{6}=3$, then $\mathbf{v}^{2}=(2,0,6,7, \emptyset, 3, \ldots, \emptyset)$. Contingent on $\mathbf{v}^{t}$, the search either ends or continues to period $t+1$. If the search procedure ends, the seller gives the good to one of the buyers. A formal definition of search procedures appears in Appendix D.

A search procedure is said to be first-best or equivalently optimal if it maximizes the expected present discounted value of the social surplus among all search procedures provided that all buyers are obedient and honest. Given our assumptions, it is trivial to show that there exists an optimal search procedure such that the good is given to the informed buyer with the highest value (for a proof, see Appendix D). Since a buyer needs to acquire information anyway before consuming, the seller has no reason to give the good to an uninformed buyer: asking the buyer to acquire information before giving him the good can only benefit the seller by allowing him to make a more efficient decision. 


\subsection{Mechanisms}

When the information acquired by the buyers is private, the seller chooses a mechanism intended to elicit this information from the buyers. In this paper we restrict attention to either auction mechanisms or to revelation mechanisms. Both types of mechanisms are designed to implement the first-best search procedure and extract the full surplus from each buyer. ${ }^{8}$ That is, they are designed to generate the first-best procedure on the equilibrium path. Therefore, in both types of mechanisms buyers are asked to acquire information in the same sequence as in the first-best search procedure. Until Section 5 we assume that information acquisition is contractible and hence do not need to worry about the buyers' incentives to acquire information when they are asked to do so. In Section 5 we will prove that the mechanism that we construct in Section 4 for the general case also provides buyers with proper incentives to acquire information. In auction mechanisms, informed buyers are asked to submit bids above reserve prices that are chosen by the seller. Given these bids, the mechanism either stops and the good is allocated to the highest bidder or it continues and additional buyers are asked to acquire information. In revelation mechanisms, informed buyers are asked to publicly announce their values as soon as they become informed and each announcement is associated with a probability of receiving the good and a transfer. To both types of mechanisms we add admission fees that each buyer commits to at the beginning of period 1 , before any buyer has acquired information, to pay the seller.

\footnotetext{
${ }^{8} \mathrm{We}$ do not prove that the types of mechanisms that we consider are the only ones that implement the first-best: there could be other types of mechanisms that will also do that.
} 


\subsection{Extracting the buyers' surplus: the efficiency principle}

The seller can charge each buyer $i$ an admission fee, $T_{i}$, equal to the buyer's expected payoff from participation in the mechanism. The admission fee, $T_{i}$, can be increased up to the point where the individual rationality constraint of buyer $i$ is just binding. Since buyers have no private information ex ante, the admission fees fully extract the expected surplus from each buyer. We refer to this fact as the efficiency principle.

Lemma 1 (The efficiency principle) For any mechanism, there exists a mechanism that yields the same outcome and gives each buyer zero ex ante surplus.

Lemma 1 implies that we only need to find a mechanism that implements the optimal search procedure. If such a mechanism exists, then, by using admission fees, the seller will be able to extract the full surplus from the buyers and his payoff will be equal to the entire social surplus generated by the optimal search.

A few remarks about Lemma 1 are in order. First, the admission fees are akin to a fixed fee in a two-part tariff. As in a two-part tariff where the per-unit price is designed to induce the buyer to make an optimal purchasing decision while the fixed fee extracts the buyer's surplus, here the socially efficient mechanism implements the first-best search procedure, while the admission fees fully extract the bidders' surplus. The difference however is that achieving social efficiency in our dynamic search context is much more challenging than in the standard monopoly model.

Second, it should be emphasized that it is not necessarily optimal for the seller to merely extract all the surplus from the potential buyers; the seller still needs to implement a socially efficient search procedure. To illustrate this point, consider a setup with infinitely many ex ante identical 
potential buyers, and no discounting. Suppose that potential buyers acquire information simultaneously and then participate in an English auction without admission fees or reserve price. At any mixed strategy symmetric equilibrium, potential buyers will obtain a zero expected surplus and hence all the surplus will be captured by the seller. This mechanism, however, does not economize on the cost of information acquisition and hence is suboptimal. ${ }^{9}$

Third, it should be noted that the buyers do not have to actually pay the admission fees up front. The seller only needs to require each buyer to commit ex ante, to pay, when the buyer is invited to acquire information, a fee that is equal to the buyer's discounted expected surplus from participation. For instance, suppose that the discount factor is constant over time, so that $\delta_{t}=\delta$ for all $t$, and let $q_{i}$ be the probability that buyer $i$ is invited to acquire information. Then, instead of paying $T_{i}$ up front, buyer $i$ can commit ex ante to pay $\frac{T_{i}}{q_{i} \delta^{t-1}}$ in period $t$ if he is invited to acquire information in that period. The resulting expected payoffs of seller and the buyers are the same as in the case where the buyers pay admission fees up front. (See 3.3 and specially Proposition 2 for discussion of admission fees in a special case.)

\footnotetext{
${ }^{9}$ As we shall see in section 3.1, the socially efficient search procedure is such that at each period, a single potential bidder is invited to privately acquire information and announce his value. The procedure ends when one of the announced values exceeds a predetermined cutoff.
} 


\section{Sequential search with independent values}

In this section, we make three assumptions which are not used in the rest of the paper. First, the buyers' values are independently (but not necessarily identically) distributed: the distribution of buyer $i$ 's value, $F_{i}$, is smooth and independent across $i$, with support $V_{i}=[0, \bar{v}]$ for all $i$. Second, we assume that the optimal search procedure is sequential in the sense that only one buyer can acquire information in each period. ${ }^{10}$ Third, we assume that the discount factor is constant over time, so that $\delta_{t}=\delta$ for all $t$. In the next section we relax these assumptions and consider the general case in which the buyers' values are possibly correlated, the optimal search procedure may be parallel and stochastic, and the discount factor need not be constant over time.

The first-best sequential search procedure in the independent values case has been characterized by Weitzman (1979). We will first show that this procedure can be implemented by a mechanism with an attractive economic interpretation and will then specialize the problem to the case where the buyers' values are identically distributed.

\subsection{The optimal search procedure}

We begin by reviewing briefly Weitzman's characterization of the optimal search procedure. To this end, suppose that before the seller faces buyer $i$, he already has the opportunity to sell the good to someone else at a price $k$. The seller's expected discounted payoff if he asks buyer $i$ to acquire

\footnotetext{
${ }^{10}$ Vishwanath (1992) shows that the optimal search procedure must be sequential if the discount factor is close enough to 1 , or if the cost of information acquisition is sufficiently high. Institutional or physical constraints could also forbid two buyers from acquiring information at the same time.
} 
information is

$$
S_{i}(k)=\delta\left[\int_{0}^{k} k d F_{i}\left(v_{i}\right)+\int_{k}^{\bar{v}} v_{i} d F_{i}\left(v_{i}\right)-c_{i}\right] .
$$

This expression reflects the fact that if buyer $i$ 's value, $v_{i}$, falls short of $k$, then the good is sold at price $k$ but if $v_{i}$ exceeds $k$ then the good is sold at price $v_{i}$. The seller benefits from asking buyer $i$ to acquire information in period $t$ if and only if this improves his expected payoff, i.e., if $S_{i}(k)>k$. Noting that $S_{i}^{\prime}(\cdot)>0$, the equation

$$
S_{i}\left(k_{i}\right)=k_{i},
$$

implicitly defines $k_{i}$ as the cutoff such that the seller will ask buyer $i$ to become informed only if $k_{i} \geq k$. It is worth noting that $k_{i}$ depends only on the distribution of $v_{i}$ and on the cost $c_{i}$ but is independent of the distributions of other buyers' values and their costs of acquiring information. To avoid triviality we assume that $k_{i} \geq 0$ for all $i \in I$.

Weitzman proves that the optimal search procedure takes the following simple form. In any period $t=1,2, \ldots, n$, if the highest value among all informed buyers is greater than or equal to the cutoffs of all uninformed buyers, the procedure stops and the good is sold to the informed buyer with the highest value. Otherwise, the procedure continues and the seller asks the buyer with the highest cutoff among all uninformed buyers to acquire information in period $t+1$. If all buyers become informed, the good is sold to the buyer with the highest value.

\subsection{An optimal mechanism}

By the efficiency principle, it is sufficient to show that Weitzman's optimal search procedure can be implemented. The Weitzman auctions mechanism which we present below does this. In Section 
3.2.1, we present a general description of the mechanism; in Section 3.2.2, we define precisely the reserve prices that must be used in the auctions that are held at each stage of the mechanism; in Section 3.2.3 we formally state the main result of this section, Proposition 1.

\section{The mechanism}

The seller begins by labelling the buyers in a descending order of cutoffs, so that $k_{1} \geq \ldots \geq k_{N}$, and charges the buyers the appropriate admission fees that extract all their expected surplus from participating in the mechanism.

In period 1, buyer 1 is instructed to acquire information about his value. The seller then makes buyer 1 a take-it-or-leave offer at a price $p_{1}^{1}$, which we will define below; if the offer is accepted, the mechanism stops. Otherwise, the mechanism continues to period $2 .{ }^{11}$

If the mechanism reaches period $t=2, \ldots, N-1$, then buyer $t$ is instructed to acquire information. Once buyer $t$ becomes informed, buyers 1 to $t$ participate in a second-price auction with period- and buyer-specific reserve prices: the reserve price assigned to buyer $i$ in period $t$ is $p_{i}^{t}$. The mechanism stops if at least one buyer submits an eligible bid, i.e., bids a price above his reserve price. If only buyer $i$ submits an eligible bid, he obtains the good and pays $p_{i}^{t}$. If several buyers submit eligible bids, then the highest bidder obtains the good and pays the maximum of his reserve price and the highest losing eligible bid. ${ }^{12}$ If no buyer submits an eligible bid, the mechanism

\footnotetext{
${ }^{11}$ The take-it-or-leave-it offer in period 1 can be interpreted as a second-price auction with a single buyer and a reserve price $p_{1}^{1}$.

${ }^{12}$ If two or more buyers submit the same high bid, the good is allocated to either one of them with equal probability. When the buyers' values are drawn from continuous distributions that have no mass points, ties are zero probability events on the equilibrium path.
} 
continues to period $t+1$. If the mechanism reaches the final period $N$, then, after the last buyer, buyer $N$, becomes informed, the seller holds a second-price auction without reserve prices that includes all $N$ buyers.

If some buyer $i$ submits an eligible bid in any period $t<N$, then the mechanism stops for sure in that period (either buyer $i$ or another buyer who submits a higher eligible bid wins). Hence, the situation is similar to a (one-shot) second-price auction and it is therefore a dominant strategy for bidder $i$ to bid his true value. However, unlike one-shot second-price auctions, here only a subset of the potential buyers is informed in any period $t<N$ and can bid. Therefore, informed buyers may be tempted to end the mechanism "too early" in order to avoid having to compete against a larger number of informed buyers in later periods. The period- and buyer-specific reserve prices must be low enough to counteract this incentive. On the other hand, if the reserve prices are too high, informed buyers will refrain from submitting eligible bids in the hope that the mechanism will proceed, in which case they may have a another chance to win the good for a lower price. Consequently, the period- and buyer-specific reserve prices must ensure that all informed buyers will submit eligible bids in period $t$ if and only of their respective values are equal to or above the cutoff $k_{t+1}$. This ensures that the mechanism will implement the outcome of the first-best search procedure whereby search stops at period $t$ if and only if the highest known value in that period exceeds the cutoff $k_{t+1}$. In the next subsection (which the reader can skip without any loss of continuity) we derive the appropriate reserve prices.

\section{Computing the reserve prices}

We construct reserve prices such that if $v_{i}=k_{t+1}$ for some buyer $i \leq t$, then this buyer is indifferent between bidding $v_{i}$ in period $t$ or waiting for period $t+1$ to bid. We show in Appendix A that, 
because the bidders' payoffs are monotone increasing in their values, buyer $i$ will bid in period $t$ if and only if $v_{i} \geq k_{t+1}$.

Formally, for any period $t$ and any buyer $i \leq t$, let $v_{-i}^{t}$ be the maximum of the values of all buyers who are informed in period $t$ excluding buyer $i$. On the equilibrium path, buyer $i$ knows in period $t>1$ that the values of the $t-1$ buyers who became informed in periods 1 through $t-1$ must be less than $k_{t}$, otherwise at least one of these other buyers would have submitted an eligible bid in period $t-1$ and the mechanism would not have reached period $t$. Therefore, from $i$ 's viewpoint, the cumulative distribution of $v_{-i}^{t}$ conditional on $v_{-i}^{t}$ being less than $k_{t}$ is

$$
H_{-i}^{t}\left(v_{-i}^{t}\right)=\frac{F_{-i}^{t}\left(v_{-i}^{t}\right)}{F_{-i}^{t-1}\left(k_{t}\right)}
$$

where

$$
F_{-i}^{t}(\cdot)=\prod_{\substack{1 \leq j \leq t \\ j \neq i}} F_{j}(\cdot) .
$$

It is worth noting that each buyer $i \neq t$ faces $t-2$ informed buyers whose values are known to be below $k_{t}$ and one informed buyer, buyer $t$, whose value is drawn from the interval $[0, \bar{v}]$ (buyer $t$ did not participate earlier so nothing is known about his value). By contrast, buyer $t$ faces $t-1$ buyers whose values are all known to be below $k_{t}$.

Let us begin by computing $p_{i}^{N-1}$, the reserve price for buyer $i$ in period $N-1$. Since in equilibrium all other informed buyers submit eligible bids in period $N-1$ if and only if their values exceed $k_{N}$, buyer $i$ with $v_{i}=k_{N}$ can win in period $N-1$ only if $v_{-i}^{N-1}<k_{N}$ (the values of all other informed bidders are below his own so that none of them submits an eligible bid). Since 
buyer $i$ is the sole bidder whenever he wins, he ends up paying his reserve price $p_{i}^{N-1}$. Hence, his expected payoff is

$$
\left(k_{N}-p_{i}^{N-1}\right) F_{-i}^{N-1}\left(k_{N}\right) .
$$

On the other hand, if buyer $i$ waits for period $N$, he wins the auction held in period $N$ only if the values of all other bidders, including bidder $N$, are lower than his own value. On the equilibrium path, all informed buyers other than $i$ submit eligible bids in period $N-1$ if and only if their values exceed the cutoff $k_{N}$, implying that the mechanism proceeds to period $N$ with probability $F_{-i}^{N-1}\left(k_{N}\right)$. Hence, buyer $i$ 's discounted expected payoff from waiting for period $N$ is

$$
\delta F_{-i}^{N-1}\left(k_{N}\right) \int_{0}^{k_{N}}\left(k_{N}-v_{-i}^{N}\right) d H_{-i}^{N}\left(v_{-i}^{N}\right) .
$$

Therefore the reserve price $p_{i}^{N-1}$ must satisfy

$$
\left(k_{N}-p_{i}^{N-1}\right) F_{-i}^{N-1}\left(k_{N}\right)=\delta F_{-i}^{N-1}\left(k_{N}\right) \int_{0}^{k_{N}}\left(k_{N}-v_{-i}^{N}\right) d H_{-i}^{N}\left(v_{-i}^{N}\right),
$$

which, by definition of $H_{-i}^{N}(\cdot)$, is equivalent to

$$
\left(k_{N}-p_{i}^{N-1}\right) F_{-i}^{N-1}\left(k_{N}\right)=\delta \int_{0}^{k_{N}}\left(k_{N}-v_{-i}^{N}\right) d F_{-i}^{N}\left(v_{-i}^{N}\right) .
$$

For $t \leq N-2$, we obtain

$$
\begin{aligned}
\left(k_{t+1}-p_{i}^{t}\right) F_{-i}^{t}\left(k_{t+1}\right)= & \delta\left(k_{t+1}-p_{i}^{t+1}\right) F_{-i}^{t+1}\left(k_{t+2}\right) \\
& +\delta \int_{k_{t+2}}^{k_{t+1}}\left(k_{t+1}-v_{-i}^{t+1}\right) d F_{-i}^{t+1}\left(v_{-i}^{t+1}\right) .
\end{aligned}
$$


The left-hand side is similar to that of (3); it is derived from the expected payoff of buyer $i$ if he submits an eligible bid in period $t$. The right-hand side has a different form, because of the presence of the reserve price in period $t+1$ : buyer $i$ will pay $p_{i}^{t+1}$ if $v_{-i}^{t+1}<k_{t+2}$, hence the first term on the right-hand side of (4); he will pay $v_{-i}^{t+1}$ if $v_{-i}^{t+1}>k_{t+2}$, hence the second term which resembles the right-hand side of (3). Here again, the reserve prices in any period $t<N-1$ are chosen to counteract the informed buyers' temptation to end the mechanism "too early" and thereby avoid competition from a larger number of informed buyers in later periods.

\section{The main result for sequential search with independent values}

Having derived the needed reserve prices we can now state the main result in this section. The proof of Proposition 1 appears in Appendix A.

Proposition 1 In the sequential search model with independent values, the Weitzman auctions mechanism with reserve prices defined by (3) and (4) has a perfect Bayesian equilibrium that extracts the full surplus. The reserve prices for any given period $t<N$ are set below the cutoff $k_{t+1}$ associated with searching for one more period.

As argued above, the reserve prices ensure that all buyers will submit eligible bids in period $t$ if and only if their respective values are equal to or above the cutoff $k_{t+1}$. Since in every period $t<N$, some buyers are still uninformed and hence cannot place bids, the reserve prices represent the future competitive pressure from these potential buyers. This pressure eliminates the incentives of informed buyers to bid "too early."

It may be worthwhile to point out that Proposition 1 does not depend crucially on the fact that only one buyer obtains information in every period. The result can be extended to any search 
procedure in which the set of buyers who acquire information in any period is independent of the past history of the procedure. For instance, a procedure with this property would have buyers 1 to 3 , say, observe their values in period 1 . If the procedure continue to a second period, then the exact number and identity of the buyers who will be asked to acquire information period 2 will be independent of $v_{1}, v_{2}$ and $v_{3} .{ }^{13}$

\subsection{An optimal mechanism when buyers are ex ante identical}

When buyers have i.i.d. values and identical search costs, Eqs. (1) and (2) imply that the cutoffs in the optimal search procedure are the same for all buyers. Therefore, the optimal search procedure functions as follows: Eq. (2) determines a common cutoff value $k$. Buyers are then examined in turn. Since one buyer is examined in every period we can use $t$ to denote both the period and the buyers who is examined in that period. The optimal search procedure stops as soon as $v_{t} \geq k$ for some $t<N$. If the procedure continues all the way to the last period, the good is allocated to the buyer with the highest value.

When we translate this into a mechanism, we see that if a buyer does not submit an eligible bid in the period in which he has acquired information, then he will not bid again until the last period. Therefore in every period $t<N$, the seller losses nothing by allowing only buyer $t$, who has just acquired information, to place an eligible bid: the mechanism is effectively equivalent to a series of take-it-or-leave-it offers, such that in period $t<N$, buyer $t$ who has just acquired information is offered the good at price $p_{t}$. If all buyers $t<N$ reject their respective offers, the seller holds in

\footnotetext{
${ }^{13} \mathrm{~A}$ preliminary version of this paper with the computations of the reserve prices for this case is available from the authors.
} 
period $N$ (after the last buyer acquires information) a second-price auction without reserve prices. The take-it-or-leave-it offers are chosen such that buyer $t<N$ will accepts the offer if and only if $v_{t} \geq k$. Apart from the take-it-or-leave-it offers, the seller charges each buyer $t$ an admission fee, $T_{t}$, at the beginning of period 1 , before any buyer has acquired information, but after the seller determines the sequence at which the buyers will be invited to acquire information.

We state this formally in the following proposition. The formal proof is provided in Appendix B.

Proposition 2 In the sequential search model with i.i.d. values and identical costs of acquiring information, there exists a sequence of take-it-or-leave-it offers followed by a second-price auction held in period $N$ such that the associated mechanism extracts the full surplus. The prices at which the good is offered are decreasing in $t$.

Assume $\delta<1$. If buyers pay the admission fees in period 1 , these fees are decreasing with $t$ : buyers who enter in later periods pay lower admission fees. On the other hand, if the admission fees are paid in the period of entry just before the buyers acquire information, they are increasing with t: buyers who enter later pay higher admission fees.

The fact that the reserve prices are decreasing has a straightforward economic explanation. For a given value, a late buyer with value $k$ who refuses to buy the good has a greater probability to acquire the good in the second-price auction held at period $N$ than does an early buyer with the same value. Therefore, to induce this late buyer to accept the offer, the seller need to offer him a lower price.

The proposition also shows that, if buyers pay their admission fee at the start of period 1, late buyers have to pay a smaller admission fee than early buyers. This reflects the fact that absent (the 
fully extracting) admission fees, a potential buyer would rather participate in the mechanism early than late: late buyers have a smaller probability of winning the good, and in expectation they win it later than early buyers. The ordering of admission fees is reversed when they are paid at the period of entry: just before acquiring information about his valuation, a late entrant faces weak competition from the buyers who entered before him, as they are known to have valuations smaller than $k$.

Burguet (1996) studies a model similar in many ways to ours. In his model, a firm looks for a long-term supplier. Potential suppliers differ in their costs, which Burguet assumes are i.i.d.. As in our model, suppliers do not know their costs ex-ante; contrary to what happens in our model, they learn their respective costs by supplying the product once. Similarly to this section, Burguet assumes that the search for the lowest cost supplier is strictly sequential in the sense that there can be only one supplier at any given period. He constructs two procurement mechanisms that implement the first-best search procedure. There are two important differences between his setup and ours. First, the "good" in Burguet's model is a long-term contract; while the search is conducted, the tenure shortens and hence the value of the "good" to the supplier decreases. Second, the cost of information acquisition is the cost of producing for one period. In terms of our model, this is equivalent to assuming that the cost $c_{i}$ of information acquisition is negatively correlated with the value $v_{i}$ of the good. This implies that the optimal search procedure does not satisfy the constant reservation price property, and that it is not possible to implement the first-best procedure through a sequence of take-it-or-leave-it offers. 


\subsection{A numerical example}

The following example illustrates the advantage of determining the set of participants via optimal search procedures rather than allowing all buyers to acquire information simultaneously before the auction begins. We also use the example to illustrate how the seller determines the admission fees that the two buyers are required to pay upfront before they acquire information. There are two buyers whose values are independently drawn from a uniform distribution on $[0,1]$. Each buyer needs to bear a cost $c<1 / 2$ to learn his value and the discount factor is equal to 1 .

In this case, Eq. (2) implies that $\int_{k}^{1}(v-k) d v=c$, or

$$
k=1-\sqrt{2 c}>0 .
$$

In the efficient search procedure, the seller invites one buyer, say buyer 1, to acquire information, reimburses $c$, and asks him to report $v_{1}$. Buyer 1 gets the good if $v_{1}>k$. Otherwise, buyer 2 acquires information, is reimbursed $c$, reports his value and the seller awards the good to the buyer with the highest value. This procedure can be implemented with the reserve prices described in Section (3.2), and yield a social surplus equal to

$$
\begin{aligned}
\int_{k}^{1}(v-c) d v+\int_{0}^{k}\left(-2 c+\int_{0}^{v} v d \tilde{v}+\int_{v}^{1} \tilde{v} d \tilde{v}\right) d v & \\
& =\frac{2}{3}-2 c+\frac{2 c \sqrt{2 c}}{3} .
\end{aligned}
$$

We now contrast this mechanism with a "free entry" mechanism in which potential buyers can acquire information simultaneously before the auction starts. By the efficiency principle, it suffices 
to contrast the expected social surplus under the two mechanisms. Under "free entry," there are four possible cases (i) both buyers acquire information simultaneously, (ii) one buyer acquires information and the other participates without information, (iii) only one buyer participates and he acquires information, and (iv) both buyers participate without acquiring information. ${ }^{14}$

In case (i), the expected social surplus is

$$
\iint_{v_{1}, v_{2}} \max \left[v_{1}, v_{2}\right] d v_{1} d v_{2}=\frac{2}{3}-2 c .
$$

In case (ii), the expected social surplus if the uninformed buyer wins is $1 / 2-c$ (the uninformed buyer still needs to spend $c$ after winning because information acquisition is assumed to "productive"). Hence, the informed buyer will win if his value, $v$, exceeds $1 / 2-c$, while the uninformed buyer will win otherwise. Hence, the expected social surplus is

$$
\int_{\frac{1}{2}-c}^{1} v d v-c+\int_{0}^{\frac{1}{2}-c}\left(\frac{1}{2}-c\right) d v=\left(\frac{1}{2}-c\right) \frac{(5-2 c)}{4} .
$$

And, in cases (iii) and (iv), the good is arbitrarily given to one buyer and $c$ is spent once. The expected social surplus is

$$
\int_{0}^{1} v d v-c=\frac{1}{2}-c .
$$

\footnotetext{
${ }^{14}$ Since $c<1 / 2$, there does not exist an equilibrium in which both buyers to stay out. Moreover, since information acquisition is productive, there also does not exist an equilibrium in which one buyer stays out and the other participates without acquiring information.
} 
Clearly, the expected surplus in Eq. (6) exceeds the expected surplus in Eq. (7). Moreover, since $c<1 / 2$, the expected surplus in Eq. (8) exceeds the expected surplus in Eq. (9). However, for all $c<1 / 2$,

$$
\frac{2}{3}-2 c+\frac{2 c \sqrt{2 c}}{3}>\left(\frac{1}{2}-c\right) \frac{(5-2 c)}{4} .
$$

Hence, the expected surplus under the efficient search mechanism exceeds the expected surplus under a "free entry" mechanism for all $c<1 / 2$.

Finally, we use the example to show that when $\delta=1$, the admission fees paid by the two bidders are equal to each other if paid in period 1 . To this end, note since there are only two buyers whose values are drawn independently from a uniform distribution on $[0,1]$, and since the discount factor is equal to 1, Eq. (3) implies the seller chooses the reserve price

$$
p=k-\int_{0}^{k}(k-v) d v .
$$

Recall that buyer 1 buys the good immediately at price $p$ if $v_{1}>k$, but buys it in period 2 at price $v_{2}$ if $v_{2}<v_{1}<k$. Therefore, the expected payoff of buyer 1 after he pays his admission fee, 
but before he incurs the cost $c$ and learns $v_{1}$, is

$$
\begin{aligned}
U_{1}= & \int_{k}^{1}\left(v_{1}-p\right) d v_{1}+\int_{0}^{k} \int_{0}^{v_{1}}\left(v_{1}-v_{2}\right) d v_{2} d v_{1}-c \\
= & \int_{k}^{1}\left(v_{1}-k+\int_{0}^{k}\left(k-v_{2}\right) d v_{2}\right) d v_{1}+\int_{0}^{k} \int_{0}^{v_{1}}\left(v_{1}-v_{2}\right) d v_{2} d v_{1}-c \\
= & \int_{k}^{1}\left(v_{1}-k-\int_{0}^{k}\left(v_{1}-k\right) d v_{2}+\int_{0}^{k}\left(v_{1}-v_{2}\right) d v_{2}\right) d v_{1} \\
& \quad+\int_{0}^{k} \int_{0}^{v_{1}}\left(v_{1}-v_{2}\right) d v_{2} d v_{1}-c \\
= & \int_{k}^{1}\left(v_{1}-k\right)(1-k) d v_{1} \\
& \quad+\left[\int_{0}^{k} \int_{0}^{v_{1}}\left(v_{1}-v_{2}\right) d v_{2} d v_{1}+\int_{k}^{1} \int_{0}^{k}\left(v_{1}-v_{2}\right) d v_{2} d v_{1}\right]-c .
\end{aligned}
$$

Similarly, the expected payoff of buyer 2 at the beginning of period 2 before he incurs the cost $c$ and learns $v_{2}$ is given by

$$
U_{2}=\int_{0}^{k} \int_{0}^{v}\left(v_{1}-v_{2}\right) \frac{d v_{2}}{k} d v_{1}+\int_{k}^{1} \int_{0}^{k}\left(v_{1}-v_{2}\right) \frac{d v_{2}}{k} d v_{1}-c .
$$

The admission fees that the seller charges the two buyer at the beginning of period 1 are equal to their respective expected payoffs and given by $T_{1}=U_{1}$ and $T_{2}=k U_{2}$ (buyer 2 enjoys $U_{2}$ only 
if $v_{1}<k$, i.e., with probability $k$ ). Hence,

$$
\begin{aligned}
T_{1}-T_{2} & =\int_{k}^{1}\left(v_{1}-k\right)(1-k) d v_{1}-c(1-k) \\
& =(1-k)\left[\int_{k}^{1}\left(v_{1}-k\right) d v_{1}-c\right]=0,
\end{aligned}
$$

where the last equality follows from the definition of $k$. 


\section{Implementing the first-best in the general case}

In this section we turn to the general case in which the buyers' values are possibly correlated and the first-best search procedure could be stochastic with parallel search. That is, in any given period, it may be optimal for several buyers to acquire information, and the set of buyers that should become informed may depend on the information acquired so far. ${ }^{15}$ We will show that no matter how the first-best procedure looks, the seller can implement it with a revelation mechanism.

The revelation mechanism must satisfy incentive compatibility and individual rationality constraints: there must be an equilibrium of the mechanism in which all buyers announce their true values, and their expected payoffs from participation must all be nonnegative. This formulation assumes that the buyers observe previous announcements before announcing their own values.

Assumption 1 Any profile $\left(v_{i}\right)_{i \in I}$, with $v_{i} \in V_{i}$ for all $i \in I$, occurs with a positive prior probability (if types are discrete) or a positive density (if types are continuous).

Assumption 1 holds trivially when the buyers' values are independent. When buyers' values are correlated, this assumption ensures that there are no cases in which a buyer may find himself in a situation where he knows for sure that some of the buyers who have announced their values before him has lied. To illustrate, suppose that if $v_{1}=3$ then it is impossible that $v_{2}=7$. Now if $v_{2}=7$ and buyer 2 hears buyer 1 reporting $v_{1}=3$, then buyer 2 knows that buyer 1 has lied about his value. This means that it would be impossible to ensure that buyer 2 would report his value truthfully given that buyer 2 already knows that we are now off-the-equilibrium path. In other words, we show in the next theorem that there exists a Bayesian Nash equilibrium in which all

\footnotetext{
${ }^{15}$ In Appendix D we prove that a first-best search procedure exists.
} 
buyers make truthful reports. We do so by showing that given buyer $i$ 's hypothesis that all buyers who already reported their values were truthful and given his hypothesis that all future buyers will also be truthful, buyer $i$ will have an incentive to also be truthful. Assumption 1 rules out the possibility of events that can contradict buyer $i$ 's hypotheses. In Remark 3 below we will show that Assumption 1 can be replaced with a weaker assumption.

Theorem 1 Given Assumption 1, there exists an incentive feasible mechanism that implements any first-best search procedure.

Proof. Consider a first-best search procedure and recall that whenever this procedure stops, the good is allocated to the informed buyer with the highest known value. We build upon the first-best search procedure the following direct revelation mechanism. If the mechanism reaches period $t$, the seller asks the buyers $i \in I_{t}\left(\widehat{\mathbf{v}}^{t-1}\right)$ to acquire information, where $\widehat{\mathbf{v}}^{t-1}$ is the profile of values that were announced in previous periods. ${ }^{16}$ Once buyers in the set $I_{t}\left(\widehat{\mathbf{v}}^{t-1}\right)$ become informed, each of them is asked to independently announce his value and these announcements are made public. Given his report $\hat{v}_{i}$, buyer $i$ is committed to a payment scheme which we will specify shortly. The set $I_{t}$ is defined as in the first-best search procedure for all $t$ and the seller acts as if all informed buyers have announced their true values, i.e., as if $\widehat{\mathbf{v}}^{t-1}=\mathbf{v}^{t-1}$. In equilibrium, all informed buyers will indeed announce their true values.

Once the mechanism stops, the good is allocated to the informed buyer whose announced value was highest. The winner then pays the search costs incurred by all buyers who acquired information after he did while all the losing buyers pay a similar amount minus the announced

\footnotetext{
${ }^{16}$ When $t=1$ there is no profile of previously observed values, so $\mathbf{v}^{0}=(\emptyset, \emptyset, \ldots, \emptyset)$.
} 
value of the winner. In addition, each buyer pays an admission fee equal to his expected payoff from participation.

This mechanism implements the first-best search procedure if all informed buyers announce their values truthfully. We use the recursion hypothesis that all buyers have announced their true values in all previous periods, and prove that buyers in $I_{t}\left(\widehat{\mathbf{v}}^{t-1}\right)$ will do the same.

To this end, consider any first-best search procedure, and let $q_{i}\left(s, \widehat{v}_{i} \mid \widehat{\mathbf{v}}^{t-1}, v_{i}\right)$ denote the probability that buyer $i$ who acquires information in period $t$ gets the good in period $s \geq t$ if his announced value in period $t$ is $\widehat{v}_{i}$, given that the profile of values that were announced up to and including period $t-1$ is $\widehat{\mathbf{v}}^{t-1}$ and given that his own true value is $v_{i}$. In addition, let $Z_{-i t}\left(\widehat{v}_{i} \mid \widehat{\mathbf{v}}^{t-1}, v_{i}\right)$ be the aggregate discounted expected utility that all buyers but $i$ derive from consuming the good if buyer $i$ 's announcement in period $t$ is $\widehat{v}_{i}$, and let $C_{-i t}\left(\widehat{v}_{i} \mid \widehat{\mathbf{v}}^{t-1}, v_{i}\right)$ be the associated aggregate discounted cost that all buyers but $i$ incur when they acquiring information in period $t$ and all subsequent periods. ${ }^{17}$ Let us also define

$$
\delta_{t}^{t}:=1, \quad \delta_{t}^{s+1}:=\delta_{t}^{s} \delta_{s}, \quad s=t, t+1, \ldots, N .
$$

Then, the discounted expected utility of buyer $i$ when he announces in period $t$ that his value is $\widehat{v}_{i}$ is

$$
v_{i} \sum_{s=t}^{\infty} \delta_{t}^{s} q_{i}\left(s, \widehat{v}_{i} \mid \widehat{\mathbf{v}}^{t-1}, v_{i}\right)+Z_{-i t}\left(\widehat{v}_{i} \mid \widehat{\mathbf{v}}^{t-1}, v_{i}\right)-C_{-i t}\left(\widehat{v}_{i} \mid \widehat{\mathbf{v}}^{t-1}, v_{i}\right)-c_{i} .
$$

This expression is equal to the expected surplus that the seller would get in the first-best search procedure given $\mathbf{v}^{t-1}$ by deciding to follow from period $t$ onward the policy that he would have

${ }^{17}$ The probability $q_{i}\left(s, \widehat{v}_{i} \mid \widehat{\mathbf{v}}^{t-1}, v_{i}\right)$, as well as the expressions $Z_{-i t}\left(\widehat{v}_{i} \mid \widehat{\mathbf{v}}^{t-1}, v_{i}\right)$ and $C_{-i t}\left(\widehat{v}_{i} \mid \widehat{\mathbf{v}}^{t-1}, v_{i}\right)$ are well-defined. See Appendix D for details. 
followed had buyer $i$ 's value been $\widehat{v}_{i}$ instead of $v_{i}$. By revealed preferences, this expression is maximized at $\widehat{v}_{i}=v_{i}$. That is, buyer $i$ 's optimal strategy is to announce his true value. Note that Assumption 1 is crucial for the revealed preferences argument: if Assumption 1 fails, then it is possible that $\mathbf{v}^{t-1}$ is incompatible with $v_{i}$ in which case buyer $i$ realizes that at least one buyer has already misreported his value before period $t$, and he need not maximize his expected value by making a truthful report.

Several remarks about Theorem 1 are in order.

Remark 1 The mechanism that we constructed in the proof of Theorem 1 is a Groves-like mechanism. The idea is to structure the payment of each informed buyer in such a way that the buyer's problem coincides with the seller's problem in the first-best search problem. Each buyer then wishes to make a truthful report in order to allow the seller to maximize the surplus. Note however from Eq. (10) that a buyer's expected utility does depend on his belief about the values of future buyers who are yet uninformed. Hence, truth telling is not a dominant strategy equilibrium. While this mechanism is efficient, it obviously does a poor job in extracting the buyers' surplus ex post. In fact, each one of the buyers who do not get the good receives a payment equal to the value of the buyer who does get the good (minus the cost of search incurred by all other buyers who acquired information either at the same time or after). However, given that the mechanism implements the first-best search procedure, the efficiency principle ensures that the seller obtains a payoff equal to the entire increase in social surplus generated by the optimal search.

Remark 2 The proof of Theorem 1 does not depend on the assumption that buyers learn their values as soon as they spend the cost $c_{i}$. Hence, the result can be easily generalized to the case 
where it takes more than one period for buyers to discover their values or if this time would differ across different buyers. ${ }^{18}$

Remark 3 The role of Assumption 1 is to ensure that no bidder knows that the game has gone off the equilibrium path. We could weaken this assumption by making the following assumption instead:

Assumption 1' If buyer $i$ belongs to the set $I_{t}$ of buyers who are invited to enter the mechanism at period $t$ and his realized value is $v_{i}$, and if $\left(I_{1}, \ldots, I_{t-1}\right)$ is the sequence of buyers who were invited to enter in previous periods, then there exists a profile $\mathbf{v}^{t-1}$ of realized values of these earlier entrants such that $\left(\mathbf{v}^{t-1} ; v_{i}\right)$ has a positive probability (with discrete types) or positive density (with continuous types) and the first-best search procedure given $\mathbf{v}^{t-1}$ asks buyers in $I_{t}$ to enter in period $t$.

Roughly speaking, Assumption 1' ensures that a buyer cannot infer only on the basis of his place in the sequence that some other buyer ahead of him in the sequence must have lied. Given this assumption, consider the following modified mechanism: the seller does not make the bidders' announcements public, so when a buyer is called upon to acquire information and announce his type he only knows his place in the sequence but not the announcements of previous buyers. If the seller hears a series of announcements that are obviously false (the vector of announced values is not feasible), he penalizes heavily all buyers who have already made announcements. Otherwise, the payments are exactly as before. With this modification, the expected discounted payoff of

\footnotetext{
${ }^{18}$ This is also true for Theorem 2.
} 
each buyer $i$ is the expectation of the expression in Eq. (10), conditional on the fact that the buyer is called in period $t$. Given the modified expected payoffs, no buyer would have an incentive to lie about his value if he believes that the others buyers are truthful. By lying, a buyer could not induce other buyers to lie since the announcement are not made public and since Assumption 1' ensures that buyers cannot be sure that others must have lied just on the basis of their place in the sequence. Furthermore, given Assumption 1', a lying buyer faces a positive probability of inducing an infeasible vector of announcements in which case he is heavily penalized.

Remark 4 As noted above, Assumption 1 always holds if buyers' values are stochastically independent. Hence, in the independent values case, it is always possible to find a mechanism that implements the first-best search procedure. In this mechanism, buyer $i$ need not wait until the good is allocated to some buyer before making (or receiving) payments. To see why, note that if the buyers' values are stochastically independent then

$$
Z_{-i t}\left(\widehat{v}_{i} \mid \widehat{\mathbf{v}}^{t-1}, v_{i}\right)=Z_{-i t}\left(\widehat{v}_{i} \mid \widehat{\mathbf{v}}^{t-1}\right), \quad \forall i \in I,
$$

and

$$
C_{-i t}\left(\widehat{v}_{i} \mid \widehat{\mathbf{v}}^{t-1}, v_{i}\right)=C_{-i t}\left(\widehat{v}_{i} \mid \widehat{\mathbf{v}}^{t-1}\right), \quad \forall i \in I .
$$

That is, the aggregate discounted expected utility that all buyers but $i$ derive from consuming the good and the associated aggregate discounted cost of information acquisition that all buyers but $i$ incur in period $t$ and onward, depend only on buyer i's announcement but not on buyer $i$ 's true value. Hence, the seller can charge each buyer the amount $C_{-i t}\left(\widehat{v}_{i} \mid \widehat{\mathbf{v}}^{t-1}, v_{i}\right)-Z_{-i t}\left(\widehat{v}_{i} \mid \widehat{\mathbf{v}}^{t-1}, v_{i}\right)$ 
as soon as buyer $i$ makes his announcement. With this payment, buyer $i$ 's expected payoff will be as in Eq. (10) and buyer $i$ will have an incentive to announce his true value.

Remark 5 In the independent values case, the probability that buyer $i$ who acquires information in period $t$ gets the good in period $s \geq t$ if his announced value in period $t$ is $\widehat{v}_{i}$, is

$$
q_{i}\left(s, \widehat{v}_{i} \mid \widehat{\mathbf{v}}^{t-1}, v_{i}\right)=q_{i}\left(s, \widehat{v}_{i} \mid \widehat{\mathbf{v}}^{t-1}\right), \quad \forall i \in I \text {. }
$$

That is, this probability depends only on buyer $i$ announcement but not on his true value. Since in equilibrium all buyers announce their true values, the discounted probability that buyer $i$ will get the good when the buyer learns in period $t$ that is value is $v_{i}$ is therefore

$$
Q_{i t}\left(v_{i} \mid \mathbf{v}^{t-1}\right)=\sum_{s=t}^{\infty} \delta_{t}^{s} q_{i}\left(s, v_{i} \mid \mathbf{v}^{t-1}\right)
$$

Since the mechanism implements the first-best search procedure, $Q_{i t}\left(v_{i} \mid \mathbf{v}^{t-1}\right)$ is also the discounted probability that buyer $i$ gets the good in the first-best search procedure when he learns in period $t$ that his value is $v_{i}$ and given that the vector of values of all buyers who have learned their values up to and including period $t$ is $\mathbf{v}^{t-1}$.

It is possible to show the following proposition (see Appendix $\mathrm{C}$ for a proof):

Proposition $3 Q_{i t}\left(v_{i} \mid v^{t-1}\right)$ is (weakly) monotone increasing in $v_{i}$ for any $t=1,2, \ldots$ and any informed buyer $i$. 
This proposition has an important consequence for the type of mechanism that can be implemented. The payment of buyer $i$ can then take the form

$$
\int_{v_{i}^{\min }}^{v_{i}^{\prime}} \frac{\partial Q_{i t}\left(z \mid v^{t-1}\right)}{\partial z} z d z,
$$

where $v_{i}^{\min }$ is the minimum $v_{i}$ in $V_{i}$ and $v_{i}^{\prime}$ is his announcement. ${ }^{19}$ Indeed, when his type is $v_{i}$, buyer $i$ chooses his announcement $v_{i}^{\prime}$ so as to maximize

$$
\begin{aligned}
v_{i} Q_{i t}\left(v_{i}^{\prime} \mid\right. & \left.v^{t-1}\right)-\int_{v_{i}^{\min }}^{v_{i}^{\prime}} \frac{\partial Q_{i t}\left(z \mid v^{t-1}\right)}{\partial z} z d z \\
& =v_{i} Q_{i t}\left(v_{i} \mid v^{t-1}\right)-\int_{v_{i}^{\min }}^{v_{i}} \frac{\partial Q_{i t}\left(z \mid v^{t-1}\right)}{\partial z} z d z \\
& +\int_{v_{i}}^{v_{i}^{\prime}}\left(v_{i}-z\right) \frac{\partial Q_{i t}\left(z \mid v^{t-1}\right)}{\partial z} d z
\end{aligned}
$$

When $Q_{i t}$ is monotone, truth-telling maximizes buyer $i$ 's utility. ${ }^{20}$

Remark 6 Unlike the independent values case, when the buyers' values are not independent, the discounted probability that buyer $i$ would get the good in an optimal search procedure need not be

\footnotetext{
${ }^{19}$ This implicitly assumes that $V_{i}$ is an interval. Only technical details of no importance change if it is not.

${ }^{20}$ Of course, the fact that $Q_{i t}$ is monotone is only necessary for enabling us to build mechanisms where the payment of bidder $i$ does not depend on future bids. As Theorem 1 shows, we can implement the first best even when this assumption does not hold.
} 
increasing with his value. To see that, consider a model with two ex ante identical buyers, 1 and 2. Suppose that the discount factor is 1 and the cost of acquiring information is $c \in[1,3]$. The buyers' values, $v_{1}$ and $v_{2}$, belong to the set $\{1,3,10\}$, and their joint distribution is described by the following table:

\begin{tabular}{l|l|l|l|l|}
\multicolumn{1}{c|}{$v_{2}$} \\
\cline { 2 - 5 } \multicolumn{1}{c|}{} & 1 & 3 & 10 \\
\hline \multirow{3}{*}{$v_{1}$} & 0.28 & 0.01 & 0.01 \\
\cline { 2 - 5 } & 3 & 0.01 & 0.18 & 0.16 \\
\cline { 2 - 5 } & 10 & 0.01 & 0.16 & 0.18 \\
\hline
\end{tabular}

For instance, $\operatorname{Pr}\left(v_{1}=3, v_{2}=10\right)=0.16$. In an optimal search procedure, at least one buyer, say buyer 1 , should acquire information in period 1 , since his expected value is

$$
0.3 \times 1+0.35 \times 3+0.35 \times 10=4.85
$$

while the cost of acquiring information is at most 3 . Obviously, if $v_{1}=10$, then the mechanism should stop and buyer 1 should get the good. If $v_{1}=1$, then buyer 2's expected value, conditional on $v_{1}=1$, is

$$
\frac{0.28}{0.3} \times 1+\frac{0.01}{0.3} \times 3+\frac{0.01}{0.3} \times 10 \approx 1.37
$$

Since $c \geq 1$, continuation generates an expected surplus of at most 0.37 ; hence, it is again optimal to stop the mechanism and give the good to buyer 1 . But, $v_{1}=3$, then buyer 2 's expected value, conditional on $v_{1}=3$, is

$$
\frac{0.01}{0.35} \times 1+\frac{0.18}{0.35} \times 3+\frac{0.16}{0.35} \times 10=6.2 .
$$


Since $c \leq 3$, continuation generates an expected surplus of at least 3.2. Hence, it is now efficient to ask buyer 2 to also acquire information rather than give the good immediately to buyer 1 . The good is then allocated to the buyer with the highest value (in case of a tie the good is given to one of the buyers at random). Hence, in an optimal search procedure, buyer 1 gets the good for sure if $v_{1} \in\{1,10\}$, but if $v_{1}=3$, he gets it for sure only when $v_{2}=1$ and with some probability when $v_{2}=3$, but does not get it at all when $v_{2}=10$. 


\section{The incentive to acquire information}

Thus far we assumed that information acquisition by each buyer is contractible. That is, a court can verify whether a buyer has failed to acquire information when being asked by the seller and can impose a large penalty on the buyer in this cases. In this section we will show that this assumption is not needed: the mechanism that we constructed in Section 4 provides buyers with proper incentives to acquire information. ${ }^{21}$

In general, when information acquisition is not contractible, buyers might benefit from staying uninformed until they actually win the good (in which case they must, by assumption, acquire information before consuming the good). Being uninformed means that the buyers may not get the good when they should or get it when they should not. Nonetheless, buyers may benefit from staying uninformed since then they can save the cost of information acquisition in all the cases in which they fail to win the good. ${ }^{22}$ In the next theorem we show however that the mechanism that we constructed in Section 4 solves this incentive problem. Intuitively, the transfers in this mechanism are designed such that the expected payoff of each buyer coincides with the seller's expected surplus. Since the seller has an incentive to acquire information in the optimal search

\footnotetext{
${ }^{21}$ We continue to assume however that the seller can prevent buyers from acquiring information before they agree to participate in the mechanism. What we show then is that it is not necessary to also assume that the seller can force buyers to acquire information once they agree to participate and are instructed to learn their values. The problem that we consider in this section differs therefore from that in the literature on precontractual information acquisition in mechanism design (see Crémer and Khalil (1992), Crémer, Khalil and Rochet (1998a,b), and Lewis and Sappington (1997)) where an agent may learn his type before accepting the principal's contract.

${ }^{22}$ This consideration, which arises due to the fact that the seller faces multiple potential buyers, is completely absent in the literature on precontractual information acquisition mentioned above which considered single agent models.
} 
procedure, so will each of the buyers.

Theorem 2 The revelation mechanism characterized in Section 4 provides each buyer with proper incentives to acquire information.

Proof. We prove that the "obedient" strategy, acquiring information and reporting it truthfully, is a perfect Bayesian Nash equilibrium of the game generated by the mechanism. In order to do so, we adapt the proof of Theorem 1 to the problem of information acquisition. To this end, let $F\left(\mathbf{v} \mid \widehat{\mathbf{v}}^{t-1}\right)$ be the joint probability distribution of the values of all buyers (informed and uninformed) conditional on the information profile at the end of period $t-1: F\left(\mathbf{v} \mid \widehat{\mathbf{v}}^{t-1}\right)$ is the best estimate of buyers' values as of the end of period $t-1$.

Consider buyer $i$ who is asked by the seller to acquire information in period $t$. Given the mechanism that was constructed in Theorem 1, the discounted expected utility of buyer $i$ if he does not acquire information in period $t$ and makes the report $\widehat{v}_{i}$ is

$$
\begin{aligned}
U_{i}= & \int_{V}\left[\left(v_{i}-c_{i}\right) \sum_{s=t}^{\infty} \delta_{t}^{s} q_{i}\left(s, \widehat{v}_{i} \mid \widehat{\mathbf{v}}^{t-1}, v_{i}\right)\right. \\
& \left.+Z_{-i t}\left(\widehat{v}_{i} \mid \widehat{\mathbf{v}}^{t-1}, v_{i}\right)-C_{-i t}\left(\widehat{v}_{i} \mid \widehat{\mathbf{v}}^{t-1}, v_{i}\right)\right] d F\left(\mathbf{v} \mid \widehat{\mathbf{v}}^{t-1}\right),
\end{aligned}
$$

where $V:=\times_{i \in I} V_{i}$ is the set of all possible profiles (states of nature), and the functions $Z_{-i t}$ and $C_{-i t}$ have been defined in the proof of Theorem 1. Indeed, when buyer $i$ gets the good, he needs to spend the cost $c_{i}$ before consuming it. Buyer $i$ gets the good in period $s$ with probability $\int_{V} q_{i}\left(s, \widehat{v}_{i} \mid \widehat{\mathbf{v}}^{t-1}, v_{i}\right) d F\left(\mathbf{v} \mid \widehat{\mathbf{v}}^{t-1}\right)$. The rest of the expression shows his expected transfers from the seller. 
The report $\widehat{v}_{i}$ by buyer $i$ generates a search procedure which is a feasible solution of the search problem. The expected surplus associated with this solution is exactly equal to $U_{i}$. Because this solution is (at least weakly) dominated by the optimal search procedure, and since the optimal search procedure generates a surplus to the seller equals to the utility of buyer $i$ if he follows the obedient strategy, $U_{i}$ is smaller than the utility of the buyer if he follows that strategy. Hence, the obedient strategy is a perfect Bayesian Nash equilibrium of the game induced by the mechanism. 


\section{Conclusion}

This paper has characterize optimal selling mechanisms when buyers do not know their values at the outset and must incur a cost in order to learn these values. Unlike most of the literature on auctions with endogenous entry which assumes that all interested bidders acquire information simultaneously before the auction begins, we made the decision on who will acquire information and at what stage an integral part of the seller's problem. We showed that it is possible to construct a mechanism that leads to a full extraction of surplus: under this mechanism, the seller does as well as if he could have fully controlled the buyers' acquisition of information and learned their values at the same time as they do. Furthermore, our proofs are constructive, in the sense that they show how to build the optimal mechanism once the optimal search procedure (that specifies who should acquire information in which period and who gets the good, based on the information that has already been acquired) has been identified. In some special cases in which the optimal search procedure is known, we have identified explicitly an optimal mechanism. In more general cases, the properties of the optimal search procedure may not yet be known (the optimal search could be parallel and may depend on the history of the search up to that point). However, we wish to stress that computing the optimal search procedure is a problem for Operations Research specialists, not economists. Our paper focuses on the incentive issues that arise due to the fact that buyers may wish to avoid the cost of information acquisition and remain uninformed about their values, and may wish to misreport their private information once they do acquire information. Our main result is that once the operations research problem is solved, it is possible to implement the optimal search procedure with an incentive feasible mechanism.

Our results could be generalized in a number of dimensions. For instance, we have assumed 
that the cost of information acquisition had to be incurred before consumption can take place. This implies that there is no need to consider the possibility of selling the good to an uninformed buyer. The theory would go through basically unchanged if we allowed for sale to an uninformed buyer. We have also assumed that the buyers' participation constraints are ex ante: buyers agree to participate before they become informed. If we replace this constraint by interim participation constraints, then while it is still true that the mechanism that was constructed in Theorem 1 will implement the first-best search procedure, this mechanism will no longer enable the seller to extract the full surplus from each buyer. In Crémer, Spiegel, and Zheng (2007), we characterized the seller's optimal mechanisms in that case. ${ }^{23}$ We show that it is seller-optimal to find a winner of the good via a search procedure that maximizes the expected value of the virtual utility of the trade. Hence, the seller-optimal search procedure is usually socially inefficient and will involve too few participants, too long search conditional on the same set of participants, and inefficient sequence of entry.

Our paper also shares with the rest of the literature the assumption that the $c_{i} \mathrm{~s}$ are known to the seller; in some circumstances this might be an unreasonable assumption - it is probably more realistic to think that in general both the seller and the bidder have private information that would be useful to estimate the costs of information acquisition. We feel that there is interesting work to be done in trying to understand the consequences of less stringent assumptions on this topic. In particular, it could be that some less sophisticated mechanisms are less sensitive to bad information about these costs.

\footnotetext{
${ }^{23}$ See footnote 2 .
} 


\section{Appendices}




\section{A. Proof of Proposition 1}

To prove the proposition, we begin with the following lemma:

Lemma A.1 The reserve prices defined by Eq. (3) and (4) satisfy $p_{i}^{t}<k_{t+1}$ for all $i<N$ and all $t=i, \ldots, N-1$.

Proof. Consider $p_{i}^{N-1}$ first. The right-hand side of Eq. (3) is positive since $k_{N}>0$. Hence $p_{i}^{N-1}<k_{N}$. In general, if $p_{i}^{t+1}<k_{t+2}(\forall t=i+1, \ldots, N-1)$, then $p_{i}^{t+1}<k_{t+1}$ since $k_{t+2} \leq k_{t+1}$; hence the right-hand side of Eq. (4) is positive, implying that $p_{i}^{t}<k_{t+1}$. The lemma therefore follows by induction.

It now suffices to prove the following claim for all $t=1, \ldots, N$.

Claim A.1 The strategy profile defined below constitutes a perfect Bayesian equilibrium in the continuation game of the Weitzman auctions starting from period $t$ : In every period $t<N$, every informed buyer $i$ submits an eligible bid if and only if $v_{i} \geq k_{t+1}$ and, if he does submit an eligible bid, his bid is equal to $v_{i}$; in the final period $N$, every buyer bids his true value.

In every period $t$, Lemma A.1 implies that a buyer's minimum eligible bid is below the cutoff $k_{t+1}$. Thus, the strategy profile described above is well-defined. Our task is to prove that the profile constitutes an equilibrium.

If the mechanism reaches the final period $N$ then we have a simple second-price auction with private values. Hence it is a dominant strategy for each buyer to submit a bid equal to his value. 
Thus, the claim is true for period $N$. For future reference, let us calculate a buyer $i$ 's expected payoff at the beginning of period $N$, given his value $v_{i}$ :

$$
B_{i}^{N}\left(v_{i}\right)=\int_{0}^{v_{i}}\left(v_{i}-v_{-i}^{N}\right) d H_{-i}^{N}\left(v_{-i}^{N}\right)
$$

where $H_{-i}^{N}\left(v_{-i}^{N}\right):=\frac{F_{-i}^{N}\left(v_{-i}^{N}\right)}{F_{-i}^{N-1}\left(k_{N}\right)}$ is the cumulative distribution function of $v_{-i}^{N}$ conditional on it being less than $k_{N}$ (otherwise at least one of the buyers would have submitted an eligible bid before period $N$ in which case the mechanism would not have reached period $N$ ).

For any $t=1, \ldots, N-1$, assume that the claim is true for all periods $t^{\prime}>t$; we shall complete the proof by demonstrating the claim for period $t$. Hence consider period $t$, when the buyers $1, \ldots, t$ are already informed. If any of them submits an eligible bid in this period, then the good is sold via a second-price auction and the mechanism ends. Thus, if an informed buyer contemplates submitting an eligible bid in period $t$, his problem is essentially equivalent to a bidder's problem in a second-price auction with bidder-specific reserve prices; hence it is a dominant strategy for this buyer to bid his true value.

The remaining question for a buyer in period $t$ is whether to submit an eligible bid or not, given the equilibrium hypothesis that other buyers are truthful. Pick any such buyer $i$. If buyer $i$ submits an eligible bid, then he bids his true value $v_{i}$, as previously observed. When $v_{i} \geq k_{t+1}$, buyer $i$ wins if either no one else submits an eligible bid ( $k_{t+1}>v_{-i}^{t}$ by the equilibrium hypothesis) or the highest eligible bid from other buyers is below his bid $v_{i}\left(k_{t+1} \leq v_{-i}^{t}<v_{i}\right.$ by the equilibrium hypothesis). In the first case, buyer $i$ pays $p_{i}^{t}$, and in the second case he pays $v_{-i}^{t}$. Therefore, 
buyer $i$ 's expected payoff if he submits an eligible bid in period $t$ is:

$$
B_{i}^{t}\left(v_{i}\right)=\left\{\begin{array}{lll}
\int_{0}^{k_{t+1}}\left[v_{i}-p_{i}^{t}\right] d H_{-i}^{t}\left(v_{-i}^{t}\right) & \text { if } \quad v_{i} \geq k_{t+1}, \\
+\int_{k_{t+1}}^{v_{i}}\left[v_{i}-v_{-i}^{t}\right] d H_{-i}^{t}\left(v_{-i}^{t}\right) & & \\
\int_{0}^{k_{t+1}}\left[v_{i}-p_{i}^{t}\right] d H_{-i}^{t}\left(v_{-i}^{t}\right) & \text { if } \quad v_{i}<k_{t+1} .
\end{array}\right.
$$

Suppose that buyer $i$ does not submit an eligible bid in period $t$. We shall calculate his expected payoff $N_{i}^{t}\left(v_{i}\right)$ from this action. If someone else submits an eligible bid in this period, $i$ gets zero payoff; otherwise, the mechanism continues to period $t+1$ and buyer $i$ gets his optimal expected payoff in the continuation game starting at period $t+1$, given his equilibrium hypothesis. By the induction hypothesis, the strategy profile defined in our claim constitutes an equilibrium in this continuation game, which also fits his equilibrium hypothesis. Thus, conditional on the event that the mechanism continues to period $t+1$, buyer $i$ 's expected payoff is equal to the one generated by the scenario that all buyers, including buyer $i$, will abide to this equilibrium starting from period $t+1$. In this scenario, buyer $i$ will either submit an eligible bid in the first period $t^{\prime}$ among $\{t+1, \ldots, N\}$ such that his value is at least $k_{t^{\prime}+1}$ or, if such $t^{\prime}$ does not exist, submit a bid in the final period. Thus, when $v_{i} \geq k_{t+1}$, buyer $i$ will submit a bid in period $t+1$ because $k_{1} \geq \ldots \geq k_{N}$ implies that $v_{i} \geq k_{t+2}$. By the equilibrium hypothesis, the probability of reaching period $t+1$ from period $t$ is $H_{-i}^{t}\left(k_{t+1}\right)$; conditional on reaching period $t+1$, buyer $i$ 's expected payoff is $B_{i}^{t+1}\left(v_{i}\right)$, defined by Eqs. (A.1) and (A.2). Thus,

$$
v_{i} \geq k_{t+1} \Longrightarrow N_{i}^{t}\left(v_{i}\right)=\delta_{t} H_{-i}^{t}\left(k_{t+1}\right) B_{i}^{t+1}\left(v_{i}\right)=\delta_{t} \frac{F_{-i}^{t}\left(k_{t+1}\right)}{F_{-i}^{t-1}\left(k_{t}\right)} B_{i}^{t+1}\left(v_{i}\right) .
$$


In general, buyer $i$ can choose to submit an eligible bid in period $t+1$ if he does not do so in period $t$; thus, for all $v_{i}$,

$$
N_{i}^{t}\left(v_{i}\right) \geq \delta_{t} H_{-i}^{t}\left(k_{t+1}\right) B_{i}^{t+1}\left(v_{i}\right)=\delta_{t} \frac{F_{-i}^{t}\left(k_{t+1}\right)}{F_{-i}^{t-1}\left(k_{t}\right)} B_{i}^{t+1}\left(v_{i}\right) .
$$

Combining these two facts, we know that the difference in buyer $i$ 's expected payoff between submitting an eligible bid in period $t$ and not submitting such a bid is

$$
B_{i}^{t}\left(v_{i}\right)-N_{i}^{t}\left(v_{i}\right)\left\{\begin{array}{lll}
=\frac{\tilde{B}_{i}^{t}\left(v_{i}\right)-\delta_{t} \tilde{B}_{i}^{t+1}\left(v_{i}\right)}{F_{-i}^{t-1}\left(k_{t}\right)} & \text { if } & v_{i} \geq k_{t+1}, \\
\leq \frac{\tilde{B}_{i}^{t}\left(v_{i}\right)-\delta_{t} \tilde{B}_{i}^{t+1}\left(v_{i}\right)}{F_{-i}^{t-1}\left(k_{t}\right)} & \text { if } & v_{i}<k_{t+1},
\end{array}\right.
$$

where $\tilde{B}_{i}^{t}\left(v_{i}\right):=F_{-i}^{t-1}\left(k_{t}\right) B_{i}^{t}\left(v_{i}\right)$. Note that $\tilde{B}_{i}^{t}$ is continuous and differentiable at $k_{t+1}$.

We are now ready to verify that it is optimal for buyer $i$ to follow the equilibrium strategy in period $t$, i.e., submit an eligible bid if and only if $v_{i} \geq k_{t+1}$. It suffices to show that $B_{i}^{t}\left(v_{i}\right) \geq N_{i}^{t}\left(v_{i}\right)$ if and only if $v_{i} \geq k_{t+1}$. By (A.3), we need only to prove that $\tilde{B}_{i}^{t}\left(v_{i}\right)-\delta_{t} \tilde{B}_{i}^{t+1}\left(v_{i}\right)$ is nonnegative for all $v_{i}>k_{t+1}$, nonpositive for all $v_{i}<k_{t+1}$, and is zero at $v_{i}=k_{t+1}$. The reserve prices $p_{i}^{t}$, defined in Eq. (3) and (4), are computed so that

$$
\tilde{B}_{i}^{t}\left(k_{t+1}\right)=\delta_{t} \tilde{B}_{i}^{t+1}\left(k_{t+1}\right)
$$


Thus, we need only to show that $\tilde{B}_{i}^{t}\left(v_{i}\right)-\delta_{t} \tilde{B}_{i}^{t+1}\left(v_{i}\right)$ is monotone nondecreasing in $v_{i}$. Hence we differentiate this function using Eqs. (A.1) and (A.2) (in case of $t=N-1$, let $k_{N+1}:=-\infty$ ):

$$
\begin{aligned}
& \frac{d}{d v_{i}}\left(\tilde{B}_{i}^{t}\left(v_{i}\right)-\delta_{t} \tilde{B}_{i}^{t+1}\left(v_{i}\right)\right) \\
& \quad=\left\{\begin{array}{lll}
F_{-i}^{t}\left(v_{i}\right)-\delta_{t} F_{-i}^{t+1}\left(v_{i}\right) & \text { if } & v_{i}>k_{t+1} \\
F_{-i}^{t}\left(k_{t+1}\right)-\delta_{t} F_{-i}^{t+1}\left(v_{i}\right) & \text { if } & k_{t+2}<v_{i}<k_{t+1} \\
F_{-i}^{t}\left(k_{t+1}\right)-\delta_{t} F_{-i}^{t+1}\left(k_{t+2}\right) & \text { if } & v_{i}<k_{t+2}
\end{array}\right.
\end{aligned}
$$

Since the values are independently distributed across buyers

$$
F_{-i}^{t+1}\left(v_{i}\right)=F_{-i}^{t}\left(v_{i}\right) \times F_{t+1}\left(v_{i}\right) .
$$

Thus, every branch of the right-hand side of Eq. (A.4) is positive. As previously noted, $\tilde{B}_{i}^{t}$ is continuous at the point $k_{t+1}$ for all $t$, hence $\tilde{B}_{i}^{t}-\delta_{t} \tilde{B}_{i}^{t+1}$ is continuous at the boundary of the branches. It follows that this function is strictly increasing, as desired. Therefore, the claim is true for all periods $t=1, \ldots, N$ by induction. This proves the proposition. 


\section{B. Proof of Proposition 2}

The sequence of take-it-or-leave-it-offers is decreasing Let $F$ be the common distribution of types of buyers. Eqs. (1) and (2) imply that the cutoff in all periods is the same and defined implicitly by

$$
\int_{k}^{\bar{v}}(v-k) d F(v)-c=\frac{(1-\delta) k}{\delta}
$$

Eq. (4) implies that, for all $t$,

$$
\begin{aligned}
& \int_{0}^{k}\left(k-p_{t}\right) d F(v)^{t-1}=\delta \int_{0}^{k}\left(k-p_{t+1}\right) d F(v)^{t} \\
& \Longrightarrow k-p_{t}=\delta\left(k-p_{t+1}\right) F(k) .
\end{aligned}
$$

By Eqs. (1) and (2), $F(k)<1$, and therefore $p_{t}>p_{t+1}$.

Admission fees We now turn to the second part of the proposition and begin by proving that the sequence of admission fees, as seen from the time of entry, is increasing.

By Eq. (3), remembering that $k_{t}=k$ for all $t$, we have

$$
k-p^{N-1}=\delta \int_{0}^{k}\left(k-v^{\prime}\right) \frac{d\left(F\left(v^{\prime}\right)^{N-1}\right)}{F(k)^{N-2}} .
$$


With Eq. (4) and $k_{t}=k_{t+1}=k$ this implies for all $m$

$$
\begin{aligned}
k-p^{N-m}=\delta( & \left.k-p^{N-m+1}\right) F(k)=\delta^{m-1}\left(k-p^{N-1}\right) F(k)^{m-1} \\
= & \delta^{m} \int_{0}^{k}\left(k-v^{\prime}\right) \frac{d\left(F\left(v^{\prime}\right)^{N-1}\right)}{F(k)^{N-2}} F(k)^{m-1}=\delta^{m} \int_{0}^{k}\left(k-v^{\prime}\right) \frac{d\left(F\left(v^{\prime}\right)^{N-1}\right)}{F(k)^{N-m-1}} .
\end{aligned}
$$

Let us call $U_{t}$ the expected payoff of buyer $t$ measured from the beginning of period $t$, absent entry fee. Because the participation constraint is binding, this will be equal to his entry fee, if paid at the same date. Then, letting the dummy $v$ represent the valuation of agent $N$ and $v^{\prime}$ the maximum valuation of buyers $1, \ldots, N-1$ we have

$$
\begin{aligned}
U_{N}+c & =\int_{0}^{k} \int_{0}^{v}\left(v-v^{\prime}\right) \frac{d F\left(v^{\prime}\right)^{N-1}}{F(k)^{N-1}} d F(v)+\int_{k}^{1} \int_{0}^{k}\left(v-v^{\prime}\right) \frac{d F\left(v^{\prime}\right)^{N-1}}{F(k)^{N-1}} d F(v) \\
& >\int_{k}^{1} \int_{0}^{k}\left(v-v^{\prime}\right) \frac{d F\left(v^{\prime}\right)^{N-1}}{F(k)^{N-1}} d F(v) \\
& >\int_{k}^{1}\left[\int_{0}^{k}(v-k) \frac{d F\left(v^{\prime}\right)^{N-1}}{F(k)^{N-1}}\right] d F(v)=\int_{k}^{1}(v-k) d F(v) .
\end{aligned}
$$


Using (B.7), we have for any $m=1, \ldots, N-1$,

$$
\begin{aligned}
& \int_{k}^{1}\left(v-p^{N-m}\right) d F(v)=\int_{k}^{1}\left[v-k+\delta^{m} \int_{0}^{k}\left(k-v^{\prime}\right) \frac{d\left(F\left(v^{\prime}\right)^{N-1}\right)}{F(k)^{N-m-1}}\right] d F(v) \\
& \quad=\int_{k}^{1}\left[(v-k)\left(1-\delta^{m} \int_{0}^{k} \frac{d\left(F\left(v^{\prime}\right)^{N-1}\right)}{F(k)^{N-m-1}}\right)+\delta^{m} \int_{0}^{k}\left(v-v^{\prime}\right) \frac{d\left(F\left(v^{\prime}\right)^{N-1}\right)}{F(k)^{N-m-1}}\right] d F(v) \\
& \quad=\int_{k}^{1}\left[(v-k)\left(1-\delta^{m} F(k)^{m}\right)+\delta^{m} \int_{0}^{k}\left(v-v^{\prime}\right) \frac{d\left(F\left(v^{\prime}\right)^{N-1}\right)}{F(k)^{N-m-1}}\right] d F(v) .
\end{aligned}
$$

Now, using Eqs. (B.8) and (B.10), and representing $U_{N-m}+c$ as the sum of the expected payoff of buyer $N-m$ in period $N-m$ and of the expected payoff in the last period, we obtain

$$
\begin{aligned}
U_{N-m}+c & =\int_{k}^{1}\left(v-p^{N-m}\right) d F(v)+\delta^{m} \int_{0}^{k} \int_{0}^{v}\left(v-v^{\prime}\right) \frac{d\left(F\left(v^{\prime}\right)^{N-1}\right)}{F(k)^{N-m-1}} d F(v) \\
& =\int_{k}^{1}(v-k)\left(1-\delta^{m} F(k)^{m}\right) d F(v)+\delta^{m} F(k)^{m}\left(U_{N}+c\right) \\
& =\int_{k}^{1}\left((v-k)\left(1-\delta^{m} F(k)^{m}\right)+\delta^{m} \int_{0}^{k}\left(v-v^{\prime}\right) \frac{d\left(F\left(v^{\prime}\right)^{N-1}\right)}{F(k)^{N-m-1}}\right) d F(v) \\
& +\delta^{m} \int_{0}^{k} \int_{0}^{v}\left(v-v^{\prime}\right) \frac{d\left(F\left(v^{\prime}\right)^{N-1}\right)}{F(k)^{N-m-1}} d F(v) \\
& =\left(1-\delta^{m} F(k)^{m}\right) \underbrace{\int_{k}^{1}(v-k) d F(v)}_{<U_{N}+c \text { by (B.9) }}+\delta^{m} F(k)^{m}\left(U_{N}+c\right) .
\end{aligned}
$$


As $\delta^{m} F(k)^{m}$ is a strictly decreasing function of $m$, we have $U_{1}+c<U_{2}+c<\ldots<U_{N}+c$, and therefore $U_{1}<U_{2}<\ldots<U_{N}$.

We now turn to the comparison of entry fees when they are paid in period 1. Absent admission fees, bidder $t$ 's period-1 discounted expected surplus is $U_{t}^{0}:=\delta^{t-1} F(k)^{t-1} U_{t}$. From the computations above and Eq. (B.5), we have

$$
\begin{aligned}
U_{N-m}-\delta^{m} F(k)^{m} U_{N} & =\left(1-\delta^{m} F(k)^{m}\right)\left(\int_{k}^{1}(v-k) d F(v)-c\right) \\
& =\left(1-\delta^{m} F(k)^{m}\right)\left(\frac{1}{\delta}-1\right) k .
\end{aligned}
$$

Hence,

$$
U_{N-m}^{0}-U_{N}^{0}=(\delta F(k))^{N-m-1}\left(1-\delta^{m} F(k)^{m}\right)\left(\frac{1}{\delta}-1\right) k .
$$

Thus, an earlier entrant has a greater period-1 surplus than bidder $N$ unless $\delta=1$, and because $(\delta F(k))^{N-m-1}\left(1-\delta^{m} F(k)^{m}\right)$ increases with $m, U_{N-m}^{0}-U_{N}^{0}$ also increases in $m$ (unless $\delta=1$ ). 


\section{Proof of Proposition 3}

From the viewpoint of an observer who knows $v_{i}$ and $\mathbf{v}^{t-1}$, the expected aggregate surplus generated by the search procedure is

$$
v_{i} Q_{i t}\left(v_{i} \mid \mathbf{v}^{t-1}\right)+Z_{-i t}\left(v_{i} \mid \mathbf{v}^{t-1}\right)-C_{i t}\left(v_{i} \mid \mathbf{v}^{t-1}\right) .
$$

Now, assume that having observed $v_{i}$ and $\mathbf{v}^{t-1}$, the seller decides to follow the policy that he would have followed had buyer $i$ 's value been $v_{i}^{\prime}$ instead of $v_{i}$. Since buyers' values are independent, the aggregate expected utility that other buyers derive from consuming the good as well as the expected future aggregate cost of information acquisition become $Z_{-i t}\left(v_{i}^{\prime} \mid \mathbf{v}^{t-1}\right)$ and $C_{i t}\left(v_{i}^{\prime} \mid \mathbf{v}^{t-1}\right)$ respectively: they depend only on the policy followed by the seller, but not on the actual value of buyer $i$. The probability that buyer $i$ would obtain the good in period $s$ becomes $Q_{i t}\left(v_{i}^{\prime} \mid \mathbf{v}^{t-1}\right)$ (again since values are independent) and the expected aggregate surplus is

$$
v_{i} Q_{i t}\left(v_{i}^{\prime} \mid \mathbf{v}^{t-1}\right)+Z_{-i t}\left(v_{i}^{\prime} \mid \mathbf{v}^{t-1}\right)-C_{i t}\left(v_{i}^{\prime} \mid \mathbf{v}^{t-1}\right) .
$$

By revealed preference, the expected aggregate surplus must be greater if the "right" policy is chosen:

$$
\begin{aligned}
v_{i} Q_{i t}\left(v_{i} \mid \mathbf{v}^{t-1}\right)+Z_{-i t}\left(v_{i} \mid \mathbf{v}^{t-1}\right)-C_{i t}( & \left.v_{i} \mid \mathbf{v}^{t-1}\right) \\
& \geq v_{i} Q_{i t}\left(v_{i}^{\prime} \mid \mathbf{v}^{t-1}\right)+Z_{-i t}\left(v_{i}^{\prime} \mid \mathbf{v}^{t-1}\right)-C_{i t}\left(v_{i}^{\prime} \mid \mathbf{v}^{t-1}\right) .
\end{aligned}
$$

The same inequality must also hold if the roles of $v_{i}$ and $v_{i}^{\prime}$ are inverted:

$$
\begin{aligned}
v_{i}^{\prime} Q_{i t}\left(v_{i}^{\prime} \mid \mathbf{v}^{t-1}\right)+Z_{-i t}\left(v_{i}^{\prime} \mid \mathbf{v}^{t-1}\right)-C_{i t}( & \left.v_{i}^{\prime} \mid \mathbf{v}^{t-1}\right) \\
& \geq v_{i}^{\prime} Q_{i t}\left(v_{i} \mid \mathbf{v}^{t-1}\right)+Z_{-i t}\left(v_{i} \mid \mathbf{v}^{t-1}\right)-C_{i t}\left(v_{i} \mid \mathbf{v}^{t-1}\right) .
\end{aligned}
$$


Adding these two inequalities and simplifying we obtain

$$
\left(v_{i}-v_{i}^{\prime}\right)\left(Q_{i t}\left(v_{i} \mid \mathbf{v}^{t-1}\right)-Q_{i t}\left(v_{i}^{\prime} \mid \mathbf{v}^{t-1}\right)\right) \geq 0 .
$$

Assuming, without loss of generality, that $v_{i}>v_{i}^{\prime}$, the result follows. 


\section{A formal definition of search procedures and a proof that first-best search procedure exists}

The proof of Theorem 1 uses constructs such as "the probability with which a bidder wins the good in period $s$ given his report in period $t$ and his true value." In this appendix we clarify the measurability requirement in the definition of search procedure in order to ensure that these constructs are well-defined once a search procedure is given.

Recall that $I$ is a finite set of potential buyers and let $2^{I}$ denote the set of all subsets of $I$. For every $i \in I$, let $V_{i} \subset \mathbf{R}$ be the set of possible values of $i$. Let $V:=\times_{i \in I} V_{i}$. An element of $V$ is written as $v=\left(v_{i}\right)_{i \in I}$, with $v_{i} \in V_{i}$. For any $J \subset I$ and any $v \in V$, let $v_{J}:=\left(v_{i}\right)_{i \in J}$ and $v_{-J}:=\left(v_{i}\right)_{i \notin J}$.

Endow $V$ with a probability measure (generated by the Borel sets), and let $F$ denote the induced distribution function. Denote $\mathbf{F}$ for this measure space. Since $I$ is finite, the $\mathbf{F}$-measurability of functions from $V$ to $2^{I}$ is well-defined.

Definition: A search procedure is a sequence $\left(\psi_{t}\right)_{t=1}^{\infty}$ of functions $\psi_{t}: V \rightarrow 2^{I}$ such that each $\psi_{t}$ is F-measurable and the following condition, stated recursively, is satisfied:

1. $\psi_{1}$ is constant on $V$. Denote $\mathcal{I}^{1}:=\psi_{1}$. Note that $\mathcal{I}^{1}$ is $\mathbf{F}$-measurable.

2. For any $t=1,2, \ldots$, if $\mathcal{I}^{t}: V \rightarrow 2^{I}$ is well-defined and $\mathbf{F}$-measurable, then for any $v, v^{\prime} \in V$, if $\mathcal{I}^{t}(v)=\mathcal{I}^{t}\left(v^{\prime}\right)$ and $v_{\mathcal{I}^{t}(v)}=v_{\mathcal{I}^{t}\left(v^{\prime}\right)}^{\prime}$, then $\psi_{t+1}(v)=\psi_{t+1}\left(v^{\prime}\right) \subseteq I \backslash \mathcal{I}^{t}(v)$.

Denote $\mathcal{I}^{t+1}(v):=\mathcal{I}^{t}(v) \cup \psi_{t+1}(v)$ for all $v \in V$. Note that $\mathcal{I}^{t+1}$ is $\mathbf{F}$-measurable because both $\mathcal{I}^{t}$ and $\psi_{t+1}$ are so. 
The interpretation of the definition is as follows. Let the state of the nature be given by $v \cdot \psi_{1}(v)$ is the set of buyers who become informed in period 1 . Part 1 of the definition implies that $\psi_{1}(v)$ is predetermined independently of $v$, and $\mathcal{I}^{1}(v)$ denotes this set. $\psi_{2}(v)$ is the set of uninformed buyers who become informed in period 2. Part 2 implies two requirements: (i) $\psi_{2}(v)$ should be a subset of $I \backslash \mathcal{I}^{1}(v)$, which is the set of potential buyers who have not been informed in period 1 , and (ii) $\psi_{2}(v)$ can vary only with the realized values $v_{\mathcal{I}^{1}(v)}$ of those who have been informed in period 1. $\mathcal{I}_{2}(v)$ then denotes the set of buyers who are informed up to the end of period 2. The search ends at the end of period $t$ if and only if $\psi_{t}(v) \neq \emptyset$ and $\psi_{t^{\prime}}(v)=\emptyset$ for all $t^{\prime}>t$.

The event "buyer $i$ wins at the end of period $t$ conditional on the fact that he gets informed in period $s$ and his report is $\hat{v}_{i}$ " (ignoring ties for simplicity) is the set of $\left(\hat{v}_{i}, v_{-i}\right)$ such that

$$
\begin{aligned}
v_{-i} & \in \times_{j \neq i} V_{j} ; \\
i & \in \psi_{s}\left(\hat{v}_{i}, v_{-i}\right) \\
\hat{v}_{i} & \geq \max \left\{v_{j}: j \in \mathcal{I}^{t}\left(\hat{v}_{i}, v_{-i}\right) \backslash\{i\}\right\} ; \\
\emptyset & =\psi_{t^{\prime}}\left(\hat{v}_{i}, v_{-i}\right), \forall t^{\prime}>t .
\end{aligned}
$$

Note that this set is $\mathbf{F}$-measurable. Note that the validity of " $i \in \psi_{s}\left(\hat{v}_{i}, v_{-i}\right)$ " is independent of the value of $\hat{v}_{i}$ (Part 2 of the definition). Denote this event by $A\left(i, s, \hat{v}_{i}, t\right)$.

The event "buyer $i$ gets informed in period $s$ and his type is $v_{i}$ and $J$ is the set of those who got informed before period $s$ and $v_{J}$ is the vector of their realized values" is the set of $\left(v_{J}, v_{i}, v_{-J \cup\{i\}}\right)$ 
such that

$$
\begin{aligned}
v_{-J \cup\{i\}} & \in \times_{j \notin J \cup\{i\}} V_{j} ; \\
J & =\mathcal{I}_{s-1}\left(v_{J}, v_{i}, v_{-J \cup\{i\}}\right) ; \\
i & \in \psi_{s}\left(v_{J}, v_{i}, v_{-J \cup\{i\}}\right) .
\end{aligned}
$$

Note that this set is $\mathbf{F}$-measurable. Denote the event by $B\left(i, s, J, v_{J}, v_{i}\right)$.

Thus, the conditional probability of $A\left(i, s, \hat{v}_{i}, t\right)$ given $B\left(i, s, J, v_{J}, v_{i}\right)$ is well-defined. This conditional probability is the $q_{i}(\cdots)$ in Theorem 1 .

Given any state $v \in V$, from the viewpoint of any period $s=1,2, \ldots$, the ex post discounted total search cost is

$$
C_{s}(v):=\sum_{t=s}^{\infty} \delta^{t-s} \sum_{i \in \psi_{t}(v)} c_{i} .
$$

Note that $C_{s}$ is a $\mathbf{F}$-measurable function on $V$, and so is $C_{s}\left(\hat{v}_{i}, \cdot\right)$ for any report $\hat{v}_{i} \in V$. Hence the conditional expectation of $C_{s}\left(\hat{v}_{i}, \cdot\right)$ given event $B\left(i, s, J, v_{J}, v_{i}\right)$ is well-defined. This expectation value is the $C(\cdot)$ in the proof of Theorem 1 . The conditional expectation $Z(\cdot)$ in that proof is similarly well-defined.

We now prove the following result:

Lemma D.2 There exists a first-best search procedure.

Proof. We shall prove by induction on the number of buyers (which is assumed to be finite). The single-buyer case is trivial. Pick any $n=1,2, \ldots$ and assume that a first-best search procedure 
always exists whenever there are at most $n$ buyers. We need only to prove the existence of firstbest search procedure for any case with $n+1$ buyers. Suppose that a nonempty subset $A \subseteq I$ of buyers have acquired information and $\mathbf{v}_{A}$ is the profile of their revealed values. Then the posterior distribution of the other buyers' values conditional on $\mathbf{v}_{A}$ is determined. Maximizing the expected social surplus conditional on this event amounts to finding a first-best search procedure for a search problem with less uninformed buyers. In this sub-problem, the "seller's value" is either the initial seller's value or the highest value among $\mathbf{v}_{A}$, whichever is larger; and $I \backslash A$ becomes the set of buyers, whose values are drawn from the posterior distribution. The induction hypothesis implies that a first-best search procedure for this sub-problem exists. Hence let $\Pi\left(A, \mathbf{v}_{A}\right)$ denote the maximum social surplus of this sub-problem. Consequently, the expected value $\bar{\Pi}(A)$ of $\Pi\left(A, \mathbf{v}_{A}\right)$, with $\mathbf{v}_{A}$ being the random variable drawn from the prior distribution, is well-defined. The first-best search procedure in the original problem amounts to maximizing $\bar{\Pi}(A)$ among all nonempty $A \subseteq I$. Since there are only finitely many such $A$, the optimum solution exists. Thus, first-best search procedure exists when the number of buyers is $n+1$, as desired. 


\section{E. References}

Bergemann, Dirk and Martin Pesendorfer (2001), "Information Structure in Optimal Auctions," Cowles Foundation Discussion Paper No. 1323.

Bergemann, Dirk and Juuso Välimäki (2002), "Information Acquisition and Efficient Mechanism Design," Econometrica, 70, 100- 1033.

Burguet, Roberto (1996), "Optimal Repeated Purchases When Sellers are Learning about Costs," Journal of Economic Theory, 68, 440-455.

Chakraborty, Indranil and Georgia Kosmopoulou. (2001), "Auctions with Edogenous Entry," Economics Letters, 72, 2, 195-200.

Crémer, Jacques and Fahad Khalil (1992), "Gathering Information Before Signing a Contract," American Economic Review, 82(3), 566-578.

Crémer, Jacques, Fahad Khalil and Jean-Charles Rochet (1998a), "Contracts and Productive Information Gathering," Games and Economic Behavior, 25(2), 174-193.

Crémer, Jacques, Fahad Khalil and Jean-Charles Rochet (1998b), "Strategic Information Gathering Before a Contract is Offered," Journal of Economic Theory, 81, 163-200.

Crémer, Jacques, Yossi Spiegel, and Charles Zheng (2006), "Optimal Search Auctions with Correlated bidder type," Economics Letters, 93, 94-100.

Crémer, Jacques, Yossi Spiegel, and Charles Zheng (2007), "Optimal Search Auctions," Journal of Economic Theory 134, 226-248.

Engelbrecht-Wiggans (1993), "Optimal Auctions Revisted," Games and Economic Behavior, 5, 227-239.

Levin, Dan and James L. Smith (1994), "Equilibrium in Auctions with Entry," American Economic 
Review, 84, 585-599.

Klemperer, Paul (1999), "Auction Theory: A Guide to the Literature," Journal of Economic Surveys, 13, 227-286.

Lewis, Tracy R. and David E. M. Sappington (1997), "Information Management in Incentive Problems", Journal of Political Economy, 105, 4, 796-821.

Matthews, Steven (1984), "Information Acquisition in Discriminatory Auctions," In Bayesian Models in Economic Theory, ed. M. Boyer and R.E. Kihlstrom. Amsterdam: North-Holland pp. 181-207.

McAfee, Preston and John McMillan (1987), "Auctions with Entry," Economics Letters, 23, 343347.

McAfee, Preston and John McMillan (1988), "Search Mechanisms," Journal of Economic Theory, 44, 99-123.

Myerson, Roger (1986), "Multistage Games with Communication," Econometrica, 54, 323-358.

Persico, Nicola (2000), "Information Acquisition in Auctions", Econometrica, 68, 1, 135-148.

Stegeman, Mark (1996), "Participation Costs and Efficient Auctions," Journal of Economic Theory, 71, 228-259.

Tan, Guofu (1992), "Entry and R\&D in Procurement Contracting," Journal of Economic Theory, 58, 41-60.

Weitzman, Martin (1979), "Optimal Search for Best Alternative," Econometrica, 47, 641-654.

Vishwanath, Tara (1992), "Parallel Search for the Best Alternative," Economic Theory, 2, 495-507. Ye, Lixin (2004), "Optimal Auctions with Endogenous Entry," Contributions to Theoretical Economics, 4, 1: Article 8. http://www.bepress.com/bejte/contributions/vol4/ iss $1 / \operatorname{art} 8$ 